\title{
ORIGINAL
}

\section{Ethical climate and intention to leave among critical care clinicians: an observational study in 68 intensive care units across Europe and the United States}

Bo Van den Bulcke ${ }^{1 *}$ (D) Victoria Metaxa ${ }^{2}$, Anna K. Reyners ${ }^{3}$, Katerina Rusinova ${ }^{4}$, Hanne I. Jensen ${ }^{5}$, J. Malmgren ${ }^{6,7}$, Michael Darmon ${ }^{8}$, Daniel Talmor ${ }^{9}$, Anne-Pascale Meert ${ }^{10}$, Laura Cancelliere ${ }^{11}$, László Zubek ${ }^{12}$, Paulo Maia ${ }^{13}$, Andrej Michalsen ${ }^{14}$, Erwin J. O. Kompanje ${ }^{15}$, Peter Vlerick ${ }^{16}$, Jolien Roels ${ }^{17}$, Stijn Vansteelandt ${ }^{17,18}$, Johan Decruyenaere ${ }^{1}$, Elie Azoulay ${ }^{8}$, Stijn Vanheule ${ }^{19}$, Ruth Piers ${ }^{20}$ and Dominique Benoit ${ }^{1}$ on behalf of the DISPROPRICUS study group of the Ethics Section of the ESICM

(c) 2019 The Author(s)

\begin{abstract}
Purpose: Apart from organizational issues, quality of inter-professional collaboration during ethical decision-making may affect the intention to leave one's job. To determine whether ethical climate is associated with the intention to leave after adjustment for country, ICU and clinicians characteristics.

Methods: Perceptions of the ethical climate among clinicians working in 68 adult ICUs in 12 European countries and the US were measured using a self-assessment questionnaire, together with job characteristics and intent to leave as a sub-analysis of the Dispropricus study. The validated ethical decision-making climate questionnaire included seven factors: not avoiding decision-making at end-of-life (EOL), mutual respect within the interdisciplinary team, open interdisciplinary reflection, ethical awareness, self-reflective physician leadership, active decision-making at end-of-life by physicians, and involvement of nurses in EOL. Hierarchical mixed effect models were used to assess associations between these factors, and the intent to leave in clinicians within ICUs, within the different countries.

Results: Of 3610 nurses and 1137 physicians providing ICU bedside care, 63.1\% and 62.9\% participated, respectively. Of 2992 participating clinicians, 782 (26.1\%) had intent to leave, of which 27\% nurses, 24\% junior and 22.7\% senior physicians. After adjustment for country, ICU and clinicians characteristics, mutual respect OR $0.77(95 \% \mathrm{Cl} 0.66-$ 0.90), open interdisciplinary reflection (OR 0.73 [95\% Cl 0.62-0.86]) and not avoiding EOL decisions (OR 0.87 [95\% Cl $0.77-0.98]$ ) were all associated with a lower intent to leave.
\end{abstract}

\footnotetext{
*Correspondence: bo.vandenbulcke@uzgent.be

${ }^{1}$ Department of Intensive Care Medicine, Ghent University Hospital, De

Pintelaan 185, Ghent, Belgium

Full author information is available at the end of the article
}

\section{实 Springer}


Conclusion: This is the first large multicenter study showing an independent association between clinicians' intent to leave and the quality of the ethical climate in the ICU. Interventions to reduce intent to leave may be most effective when they focus on improving mutual respect, interdisciplinary reflection and active decision-making at EOL.

Keywords: Intent to leave, Ethical climate, Interdisciplinary reflection, Decision-making, Respect

\section{Introduction}

It becomes more and more challenging for hospital managers worldwide to retain clinicians in intensive care units (ICU) [1-5]. Currently, about $18-23 \%$ of ICU clinicians express an intention to leave their job in the United States and Europe $[6,7]$. Besides irregular working hours and night/weekend shifts in an often chaotic and noisy environment, clinicians are increasingly confronted with morally distressing situations often related to decision-making at end-of-life (EOL) [7-13]. The combination of technical innovation, which often prevents patient's natural death, and the increasing number of potentially inappropriate admissions [7, 8, 14] render EOL decisions stressful, with postponed decision-making or even decision-paralysis as a consequence $[7,8,14]$. Whereas acute moral distress related to decision-paralysis may induce overt conflicts in the team $[10,15]$, more chronic forms of unexpressed moral distress such as frustration, guilt, maladaptive behavior, can ultimately cause job turnover [14-21]. As one of the strongest and most important predictors of actual

\section{Take-home message}

Interventions aiming to reduce or prevent intent to leave among the ICU workforce should focus on improving their ethical climate.

turnover in health care, besides job satisfaction, has been found to be turnover intention [1-6]. Past efforts to reduce burnout and job leave have mainly focused on empowering individuals' resilience skills $[5,7,9]$. However, timely sharing knowledge, experience and values between different professions within an open climate may further help in reducing moral distress and subsequently intention to leave [7-15, 20]. To our knowledge, the relationship between the intent to leave and the quality of inter-professional collaboration with regards to ethical decision-making in the ICU has never been assessed.

The main objective of this study, as shown in Fig. 1, was to assess the relationship between the quality of the ethical climate in the ICU and intent to leave after taking country, ICU, and clinician factors into account. We

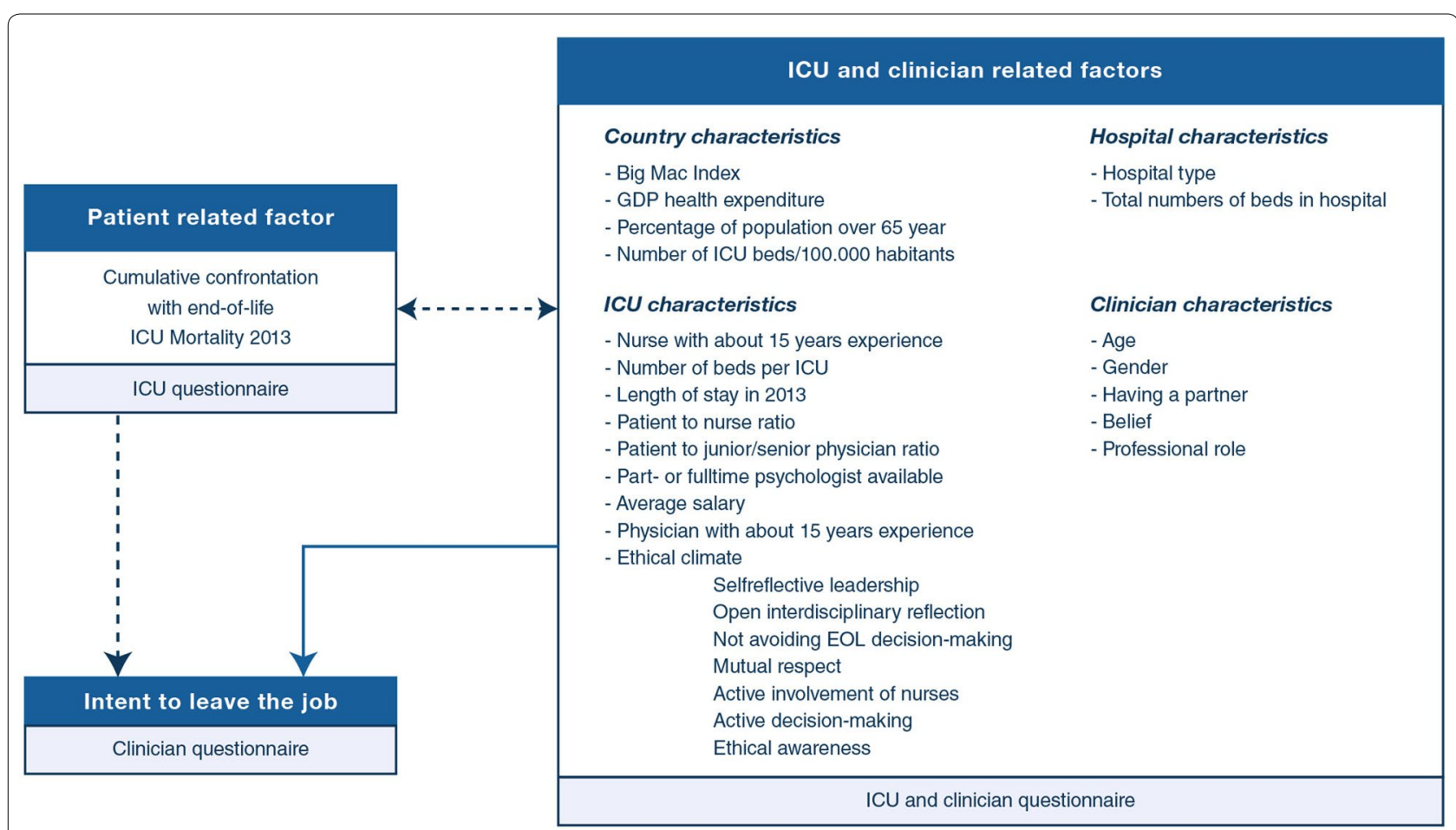

Fig. 1 Theoretical framework. ICU mortality (2013) as a surrogate marker for cumulative confrontation with end-of-life 
hypothesized that the better the quality of ethical climate in the ICU, the lower the intent to leave among clinicians.

\section{Methodology \\ Ethics}

This study was approved by the ethics committees of all participating centers and the Danish National Health Authority. Informed consent was required in all countries. The questionnaires are available in the electronic supplementary material (ESM 1).

\section{Data collection and ethical climate instruments}

This study is part of the DISPROPRICUS study, which aimed to assess whether the quality of the ethical climate in ICU is associated with the predictive value of perceptions of excessive care, in regards to patients' 1-year outcomes, as well as to the time until written treatment limitation decisions during ICU stay and death $[14,20]$.

ICU characteristics were collected by the local investigators between March and May 2014. Country-specific health variables were retrieved from a prior publication [14]. As proxy of the average wage at country level, we used countries' Big Mac index (i.e. the cost of a Big Mac in 120 different countries) as retrieved from the world bank website. This index is a global, well-known and simple economic standard reflecting countries' purchase power parity [21]. Clinicians of 68 adult ICUs in 12 European countries (Belgium, Czech Republic, Denmark, France, Germany, Greece, Hungary, Italy, Portugal, United Kingdom, Sweden, the Netherlands) and the US completed questionnaires on personal characteristics, working conditions and the ethical climate prevailing in their units using the ethical decision-making climate questionnaire (EDMCQ) [20]. This self-assessment questionnaire consists of 32 items with 4- or 5-point Likert scale options; 11 items are on end-of-life care practices [11]; 11 on interdisciplinary reflection, collaboration, and communication [22] and 11 on leadership skills of senior doctors [23, 24]. The theoretical framework of this instrument can be found in a previous publication [20]. The EDMCQ was first validated and determined via exploratory and confirmatory factor analysis, which identified seven important factors: F1 culture of not avoiding EOL decisions; F2 culture of mutual respect within the interdisciplinary team; F3 practice and culture of open interdisciplinary reflection; F4 self-reflective and empowering leadership by physician; F5 practice and culture of ethical awareness; F6 active decision-making by physicians; F7 active involvement of nurses in EOL care and decision-making [20]. Cluster analysis was subsequently used to determine categorically which kind of ethical decision climate characterized each of the ICUs [20, 25]. This analysis yielded four mutually exclusive climates: good, average with ${ }^{(+)}$and average without ${ }^{(-)}$involvement of nurses at end-of-life, and poor. The risk of death and of receiving a written treatment-limitation decision in patients perceived by clinicians as receiving excessive care was higher in ICUs with a good climate than in those with a poor one. The differences in these endpoints between the average and the poor climates were less obvious, but still in favor of the former compared to the latter, thus objectively validating the EDMCQ instrument [14, 20].

Next to the measured demographical characteristics, clinicians were also asked to report whether they actively considered leaving their current job [20, 14]. Although intention to leave is not always followed by action, the reverse relationship always exists, and intent can manifest itself some time before (from months to years) actually leaving the job [6]. For this reason, the intent to leave is presently regarded as "the most direct and immediate antecedent of overt turnover behavior" [26].

\section{Data analysis}

The primary endpoint of this study is intent to leave categorized as a binary (yes or no) outcome.

\section{Univariate analysis}

Fisher's exact tests and Pearson Chi-square tests were used for comparing categorical variables and MannWhitney $U$ tests (or $t$ test where appropriate) for comparing continuous variables. Results are presented as numbers (\%) and medians (25th-75th percentiles). Twosided $p$ values were calculated and compared with $5 \%$ to identify potential variables for inclusion in a subsequent multivariate analysis.

\section{Multivariate analysis}

We performed two hierarchical logistic mixed effect models to assess the multivariate associations between the characteristics reported in Table 1 and intention to leave, with independent random effects at the level of ICU and countries to account for correlation between measurements obtained in the same ICU, hospital and country [25]. The first model, including the four EDMCQ clusters, provides insight into the association between the overall quality of the ethical climate in a unit and intent to leave. The second model, including the seven EDMCQ factors, provides more detailed information on the association between each of the EDMCQ factors and clinicians' intent to leave their job in a unit.

The models were built using a backward elimination method. In particular, we started with a full model, including all characteristics that were identified as significantly associated with intent to leave at the $5 \%$ significance level in the univariate analysis and proceeded by removing characteristics with the highest $p$ value, 
Table 1 Intent to leave: univariate analysis*

\begin{tabular}{|c|c|c|c|c|}
\hline \multirow[t]{2}{*}{ Variables } & \multirow[t]{2}{*}{ Overall } & \multicolumn{2}{|c|}{ Intent to job leave } & \multirow[t]{2}{*}{$p$ value } \\
\hline & & Yes & No & \\
\hline Overall respondent & $n=2992$ & $n=782(26.1 \%)$ & $n=2210(73.9 \%)$ & \\
\hline \multicolumn{5}{|l|}{ Country level } \\
\hline \multicolumn{5}{|l|}{ General economic factors (25th-75th percentile) } \\
\hline Percentage of inhabitants $>65$ year & $18.0(18.0-20.0)$ & $18.0(18.0-20.0)$ & $18.0(18.0-20.0)$ & 0.823 \\
\hline Number of ICU beds $/ 100,000$ inhabitants & $6.7(6.4-15.9)$ & $6.7(6.0-12.5)$ & $6.7(6.4-15.9)$ & 0.016 \\
\hline GDP** per inhabitant (dollar) $(\times 1000)$ & $41.8(30.8-48.1)$ & $41.8(30.8-51.8)$ & $41.8(30.7-48.1)$ & 0.159 \\
\hline GDP health expediture (\%) & $10.6(9.7-11.7)$ & $9.8(9.7-11.3)$ & $11.2(9.7-12.9)$ & $<0.001$ \\
\hline GDP health expenditure per capita (x 1000) & $5.1(3.2-6.1)$ & $5.1(3.2-6.1)$ & $5.1(3.2-6.1)$ & 0.498 \\
\hline Big Mac index ${ }^{* * *}$ & $4.3(4.0-4.8)$ & $4.4(4.0-4.9)$ & $4.3(4.0-4.8)$ & $<0.001$ \\
\hline \multicolumn{5}{|l|}{ Geographical region (\%) } \\
\hline Northern Europe & $674(22.5 \%)$ & $228(33.8 \%)$ & $446(66.7 \%)$ & $<0.001$ \\
\hline Western Europe/VS & $1468(49.1 \%)$ & $337(22.9 \%)$ & $1131(77.1 \%)$ & \\
\hline Central Europe & $513(17.1 \%)$ & $123(23.9 \%)$ & $390(76.1 \%)$ & \\
\hline Southern Europe & $337(11.3 \%)$ & $94(27.9 \%)$ & $243(72.1 \%)$ & \\
\hline \multicolumn{5}{|l|}{ Hospital level (\%) } \\
\hline \multicolumn{5}{|l|}{ Hospital type } \\
\hline University & $1787(59.7 \%)$ & $458(25.6 \%)$ & $1329(74.4 \%)$ & 0.671 \\
\hline University affiliated & $364(12.2 \%)$ & $104(28.6 \%)$ & $260(71.4 \%)$ & \\
\hline Hospital & $749(25.0 \%)$ & $201(26.8 \%)$ & $548(73.2 \%)$ & \\
\hline Private & $92(3.1 \%)$ & 19 (20.7\%) & $73(79.3 \%)$ & \\
\hline \multicolumn{5}{|l|}{ Total beds in hospital } \\
\hline$<250$ & $147(4.9 \%)$ & $40(27.2 \%)$ & $107(72.8 \%)$ & $<0.001$ \\
\hline $250-499$ & $689(23.0 \%)$ & $207(30.0 \%)$ & $482(70.0 \%)$ & \\
\hline $500-749$ & $581(19.4 \%)$ & $168(28.9 \%)$ & $413(71.1 \%)$ & \\
\hline$>750$ & $1575(52.6 \%)$ & $367(23.3 \%)$ & $1208(76.7 \%)$ & \\
\hline \multicolumn{5}{|l|}{ ICU level (25th-75th percentile) } \\
\hline \multicolumn{5}{|l|}{ General } \\
\hline Number of beds per ICU & $13.0(9.0-22.0)$ & $12.0(9.0-16.0)$ & $13.0(9.0-24.0)$ & $<0.001$ \\
\hline \multicolumn{5}{|l|}{ Severity of illness } \\
\hline ICU mortality in 2013 (in \%) & $13.0(8.0-18.0)$ & $14.0(8.0-18.0)$ & $13.0(8.0-18.0)$ & $<0.001$ \\
\hline Length of stay in 2013 (in days) & $4.0(3.1-6.0)$ & $4.6(3.1-6.0)$ & $4.0(3.0-6.0)$ & 0.057 \\
\hline \multicolumn{5}{|l|}{ Organizational factors } \\
\hline \multicolumn{5}{|l|}{ Staffing } \\
\hline Patient to nurse ratio & $1.7(1.0-2.0)$ & $1.5(1.0-2.0)$ & $2.0(1.0-2.0)$ & 0.311 \\
\hline Patient to junior physician ratio & $4.0(2.0-6.0)$ & $4.0(2.0-5.8)$ & $4.0(2.0-6.0)$ & 0.073 \\
\hline Patient to senior physician ratio & $6.0(3.0-8.0)$ & $6.0(3.0-8.0)$ & $7.0(3.0-8.0)$ & 0.109 \\
\hline Part- of fulltime psychologist available & $1760(58.8 \%)$ & $479(61.3 \%)$ & $1281(57.9 \%)$ & 0.118 \\
\hline Physician salary (Euro x 1000) (15 years of working experience) & $5.0(3.2-7.3)$ & $4.9(3.2-6.3)$ & $5.0(3.2-7.3)$ & 0.005 \\
\hline Nurse salary (Euro x 1000) (15 years of working experience) & $2.5(1.9-2.8)$ & $2.6(1.9-2.9)$ & $2.5(1.9-2.8)$ & 0.013 \\
\hline \multicolumn{5}{|l|}{ Ethical decision-making climate (\%) } \\
\hline Good & $535(17.9 \%)$ & $162(30.3 \%)$ & $373(69.7 \%)$ & 0.607 \\
\hline Average with nurse involvement at EOL & $1253(41.9 \%)$ & $332(26.5 \%)$ & $921(73.5 \%)$ & \\
\hline Average without nurse involvement at EOL & $302(10.1 \%)$ & $65(21.5 \%)$ & $237(78.5 \%)$ & \\
\hline Poor & $902(30.1 \%)$ & $223(24.7 \%)$ & $679(75.3 \%)$ & \\
\hline \multicolumn{5}{|l|}{ Clinicians level (\%) } \\
\hline Age (25th-75th percentile) & $38.0(30.0-47.0)$ & $37.0(30.0-45.0)$ & $39.0(30.0-48.0)$ & 0.002 \\
\hline Male gender & $858(28.7 \%)$ & $224(26.1 \%)$ & $634(73.9 \%)$ & 0.99 \\
\hline Having a partner & $2300(76.9 \%)$ & $561(24.4 \%)$ & $1739(75.6 \%)$ & $<0.001$ \\
\hline
\end{tabular}


Table 1 (continued)

\begin{tabular}{|c|c|c|c|c|}
\hline \multirow[t]{2}{*}{ Variables } & \multirow[t]{2}{*}{ Overall } & \multicolumn{2}{|c|}{ Intent to job leave } & \multirow[t]{2}{*}{$p$ value } \\
\hline & & Yes & No & \\
\hline Having children & $1754(58.6 \%)$ & $431(24.6 \%)$ & 1323 (75.4\%) & 0.023 \\
\hline \multicolumn{5}{|l|}{ Religion } \\
\hline Non-religious & 1190 (39.8\%) & $299(25.1 \%)$ & 891 (74.9\%) & 0.587 \\
\hline Roman catholic & 687 (22.9\%) & $184(26.8 \%)$ & $503(73.2 \%)$ & \\
\hline Protestant & $534(17.8 \%)$ & $150(28.1 \%)$ & $384(71.9 \%)$ & \\
\hline Greek-orthodox & $179(5.9 \%)$ & $36(20.1 \%)$ & $143(79.9 \%)$ & \\
\hline Muslim & $30(1.0 \%)$ & $11(36.6 \%)$ & $19(63.4 \%)$ & \\
\hline Jewish & $9(0.3 \%)$ & $4(44.4 \%)$ & $5(65.6 \%)$ & \\
\hline Budhist & $10(0.3 \%)$ & $3(33.3 \%)$ & $7(66.6 \%)$ & \\
\hline Other & $162(5.4 \%)$ & $51(31.5 \%)$ & $111(68.5 \%)$ & \\
\hline I do not wish to answer & $191(6.4 \%)$ & $44(5.6 \%)$ & $147(6.7 \%)$ & \\
\hline Belief important to very important in attitude towards EOL & $453(15.1 \%)$ & $132(23.0 \%)$ & $321(77.0 \%)$ & 0.128 \\
\hline \multicolumn{5}{|l|}{ Role } \\
\hline Nurses & $2275(76.0 \%)$ & $615(27.0 \%)$ & $1660(73.0 \%)$ & 0.043 \\
\hline Junior physicians & $308(10.3 \%)$ & $74(24.0 \%)$ & $234(76.0 \%)$ & \\
\hline Senior physicians & $409(13.7 \%)$ & $93(22.7 \%)$ & $316(77.3 \%)$ & \\
\hline Years of experience in the ICU (25th-75th percentile) & $8.0(3.0-16.0)$ & $7.0(3.0-13.8)$ & $8.0(3.0-18.0)$ & 0.001 \\
\hline \multicolumn{5}{|l|}{ Working conditions (25th-75th percentile) } \\
\hline Hours working in a week & $38.0(32.0-40.0)$ & $38.0(35.0-40.0)$ & $38.0(32.0-40.0)$ & 0.048 \\
\hline Night shifts per month & $5.0(3.0-7.0)$ & $5.0(3.0-7.0)$ & $5.0(3.0-7.0)$ & 0.256 \\
\hline Day shifts during weekend per month & $3.0(2.0-4.0)$ & $4.0(2.0-5.0)$ & $3.0(2.0-4.0)$ & $<0.001$ \\
\hline Involved in research or ICU working group & $1084(36.2 \%)$ & $285(26.3 \%)$ & $799(73.7 \%)$ & 0.919 \\
\hline Ever been involved in medico-legal claim & $258(8.6 \%)$ & $75(29.1 \%)$ & $183(70.9 \%)$ & 0.295 \\
\hline
\end{tabular}

*Results are expressed by Chi square test as numbers (\%) percentages out of the total number of participants (2992), and by Kruskal test as median (25th-75th percentile), **GDP: measure of a country's economic output, gross domestics product; ***Big Mac index: the cost of a Big Mac in 120 different countries) as retrieved from the world bank website

one by one recursively, until the $p$ values for all characteristics were below 0.1 . We checked for the presence of significant interaction effects. The sole interaction effect $(p=0.02)$ that was significant at the $5 \%$ level, namely between role and hours, was included in the final models. Results of the association between ethical climate clusters and factors were expressed in (adjusted) odds ratios (OR) together with $95 \%$ confidence intervals. To aid interpretation, the results from the fitted models were standardized to adjusted percentages for the entire population, using direct standardization [25]. In the standardization process, random effects were repeatedly drawn randomly from normal distributions centred at zero with variance given by its residual maximum likelihood estimate [27]. Approximate normal-based 95\% confidence intervals for these adjusted percentages were calculated; in these, the sampling variance was obtained as the sampling variance of the standardized percentages upon ignoring the imprecision in the estimated regression coefficients, plus the variability in these percentages as the regression coefficients are repeatedly drawn from their (multivariate) sampling distributions centred at the maximum likelihood estimates. The analysis was performed in RStudio, version 1.0.15.

Since intention to leave is analyzed in a multi-level analysis approach, we also assessed which parts of the variance of intention to leave are on the country, ICU and the individual clinician level (Statistical Appendix).

\section{Results}

Country-, ICU- and clinician variables are reported in Table 1. Of 3610 nurses and 1137 physicians providing ICU bedside care, 2275 (63.1\%) and 717 (62.9\%), of which junior physicians 308 (61.5\%) and 409 (63\%) senior physicians working in 68 ICUs participated, respectively.

Respectively, $17.9 \%, 41.9 \%, 10.1 \%$ and $30.1 \%$ of clinicians worked in an ICU with a good, average ${ }^{(+)}$, average $^{(-)}$and poor climate. Overall, 782 clinicians (26.14\%) had the intention to leave their job, of which 615 (27.0\%) were nurses, 74 (24.0\%) junior physicians, and 93 (22.7\%) senior physicians. 
Table 2 Multivariate analyses on intent to leave (adjusted odds ratio [95\% confidence interval])

\begin{tabular}{|c|c|c|}
\hline & Model including EDMCQ clusters & $\begin{array}{l}\text { Model including EDMCQ } \\
\text { factors }\end{array}$ \\
\hline \multicolumn{3}{|l|}{ Country } \\
\hline Big mac index & $1.65[1.05,2.60]^{b}$ & $1.86[1.14,2.88]^{b}$ \\
\hline Healthcare expenditure per capita (divided by 100) & NS & NS \\
\hline Percentage over 65 years & NS & NS \\
\hline \multicolumn{3}{|l|}{ Hospital } \\
\hline Number of beds & NS & NS \\
\hline \multicolumn{3}{|l|}{$\mathrm{ICU}$} \\
\hline Patient to nurse ratio & NS & $0.76[0.61,0.95]^{b}$ \\
\hline Patient to junior physician ratio & NS & NS \\
\hline Psychologist available & NS & NS \\
\hline Total number of beds ICU & NS & NS \\
\hline ICU mortality in 2013 & $1.03[1.003,1.05]^{b}$ & $1.03[1.005,1.05]^{b}$ \\
\hline \multicolumn{3}{|l|}{ Ethical climate } \\
\hline Good & $0.58[0.35,0.96]^{b}$ & - \\
\hline Average $^{+}$ & $0.68(0.46-0.99)^{b}$ & - \\
\hline Average $^{-}$ & $0.62[0.40,0.98]^{b}$ & - \\
\hline Poor & 1 & - \\
\hline \multicolumn{3}{|l|}{ Factors EDM climate } \\
\hline Not avoiding EOL decisions & - & $0.87[0.77,0.98]^{b}$ \\
\hline Mutual respect & - & $0.77[0.66,0.90]^{c}$ \\
\hline Open interdisciplinary reflection & - & $0.73[0.62,0.86]^{d}$ \\
\hline Self-reflective leadership & - & NS \\
\hline Ethical awareness & - & NS \\
\hline Active decision making & - & $0.87[0.75,1.006]^{a}$ \\
\hline Active involvement of nurses & - & NS \\
\hline \multicolumn{3}{|l|}{ Clinician } \\
\hline Medicolegal claim & NS & NS \\
\hline Age & $0.98[0.97,0.99]^{d}$ & $0.98[0.97,0.99]^{d}$ \\
\hline Gender & NS & NS \\
\hline Hours worked per week & NS & NS \\
\hline \multicolumn{3}{|l|}{ Belief } \\
\hline (Very) important & NS & NS \\
\hline Not religious & NS & NS \\
\hline Not (very) important & NS & NS \\
\hline \multicolumn{3}{|l|}{ Professional role } \\
\hline Nurse & $0.27[0.09,0.82]^{b}$ & $0.18[0.06,0.55]^{b}$ \\
\hline Junior doctor & $0.27[0.06,1.12]^{a}$ & $0.22[0.05,1.01]^{\mathrm{a}}$ \\
\hline Senior doctor (Ref) & 1 & 1 \\
\hline \multicolumn{3}{|c|}{ Interaction between professional role and hours worked per week* } \\
\hline Nurse & $1.03[1.01-1.06]^{b}$ & $1.03[1.01-1.06]^{c}$ \\
\hline Junior doctor & $1.02[0.99-1.05]^{a}$ & NS \\
\hline Senior doctor (Ref) & 1 & 1 \\
\hline Intercept of model & $0.12[0.01,1.11]^{a}$ & $0.11[0.01,1.21]^{\mathrm{a}}$ \\
\hline
\end{tabular}

Data used of resp. 2992. Results of the association between ethical climate clusters and factors were expressed in (adjusted) odds ratios (OR) together with $95 \%$ confidence intervals

*Interaction effect between professional role and hours worked per week as shown in Fig. 3

a $p<0.10$

b $p<0.05$

c $p<0.01$

d $p<0.001$ 


\section{Ethical decision-making climate}

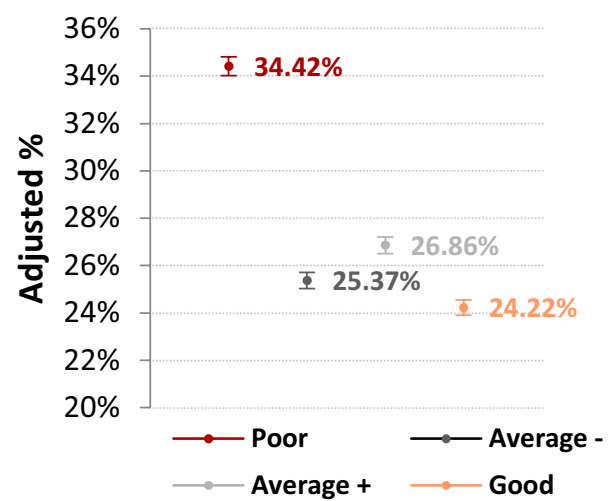

Fig. 2 Adjusted probabilities to leave one's job in the respective climates (all $p<0.05$ in comparison to the poor climate). Adjusted risk of intent to job leave, expressing the percentage of health care professionals who would have intentions to leave their job if they all worked in a good, average ${ }^{+}$, average ${ }^{-}$or poor ethical climate, respectively, along with 95\% confidence intervals. (Poor: 0.3442 $[0.3402,0.3481]$, average ${ }^{+}: 0.2686[0.26510,0.2720]$, average ${ }^{-}: 0.2537$ [0.2503,0.2570], good: $0.24[0.2389,0.2455])$

Differences between clinicians with and without intent to leave are provided in Table 1. After adjusting for clinicians' characteristics within an ICU and country, the risk of intent to leave was lower in clinicians working in ICUs in a good (OR 0.58, 95\% CI 0.35-0.96), average $^{(+)}$(OR 0.68, 95\% CI 0.46-0.99) and average $\mathrm{e}^{(-)}$ (OR 0.62, 95\% CI 0.40-0.98) climate compared to clinicians working in ICUs with a poor climate. Results are provided in Table 2. The adjusted probabilities to leave one's job in the respective climates are shown in Fig. 2 (all $p<0.05$ in comparison to the poor climate). The most important independent ethical climate factors associated with intent to leave were mutual respect within the interdisciplinary team (OR 0.77 95\% CI 0.66-0.90), open interdisciplinary reflection (OR 0.73 95\% CI 0.62-0.86) and not avoiding EOL decisions by physicians (OR 0.87 95\% CI 0.77-0.98) (Table 2). Interestingly, younger age, clinicians working in countries with a higher Big Mac index and clinicians working in ICUs with a higher mortality, were independent factors, significantly associated with a higher intent to job leave in both models (with a $p<0.05$ ). Figure 3 shows a significant interaction effect between professional role and average hours per week of clinicians as associated with intent to leave. Clinicians who worked more hours per week had a higher intent to leave, especially if they were in a nursing role $(p=0.004)$.

\section{Discussion}

This is the first large multicenter study showing that the quality of the ethical climate in ICU is associated with the intention to leave one's job, even after accounting for the impact of country, ICU and clinician characteristics. Measuring ethical climate by means of the EDMCQ [20] helped to identify several modifiable factors, which could be targeted to reduce intent to leave in the ICU.

Moreover, our study reveals that job mobility is more substantial in countries with a higher purchasing power $[2,6,21,28]$, and confirms that younger ICU clinicians tend to be less afraid to leave their current workplace $[28,29]$. These results suggest that less modifiable external/environmental factors (e.g., labor market, perceived employment opportunities, job alternatives, economic concerns,...) and clinician characteristics (e.g. age) might play an important role in ICU clinicians' intention or willingness to enter, leave or remain in the current job, profession and/or the organization as well [16, 29, 30].

Although pay and financial benefits may substantially help in reducing the intent to leave an $\operatorname{ICU}$ job $[6,28,30]$, creating favorable working conditions for clinicians by ensuring a right work-family balance and lowering the work pressure $[1,2,28,30]$ may be at least as important. Limiting the number of working hours per week is one of the measures to achieve this goal and has already been identified as an important factor in several previous studies $[2,5,6,30]$. We found that this was specifically more important in nurses (Fig. 3).

Extending previous research on the detrimental effect of high mortality in the ICU on workload, moral distress and burnout [7, 8, 11, 31], our study highlights its positive association with intent to leave. This suggests that intent to leave could be further reduced by improving triage and advanced care planning before ICU admission [32]. Moreover, our study showed a protective association between the quality of the ethical climate and intent to leave in the ICU which is in line with contemporary studies where lack of collaboration, disrespectful communication and distrust among team members are recognized as direct factors of increased job dissatisfaction and moral distress among ICU clinicians [7, 19, 33-36].

Moral distress occurs when an individual's moral integrity is seriously compromised, either because one feels unable to act in accordance with core values or obligations, or attempted actions fail to achieve the desired outcome [37]. Therefore, moving from pure knowledgebased discussions to more knowledge and value-based reflections may be of utmost importance to reduce clinicians' moral distress $[14,15,20]$ and quality of care $[7$, $8,14,32]$. Mutual respect which allows interdisciplinary reflection [33, 36, 39], together with the non-avoidance 


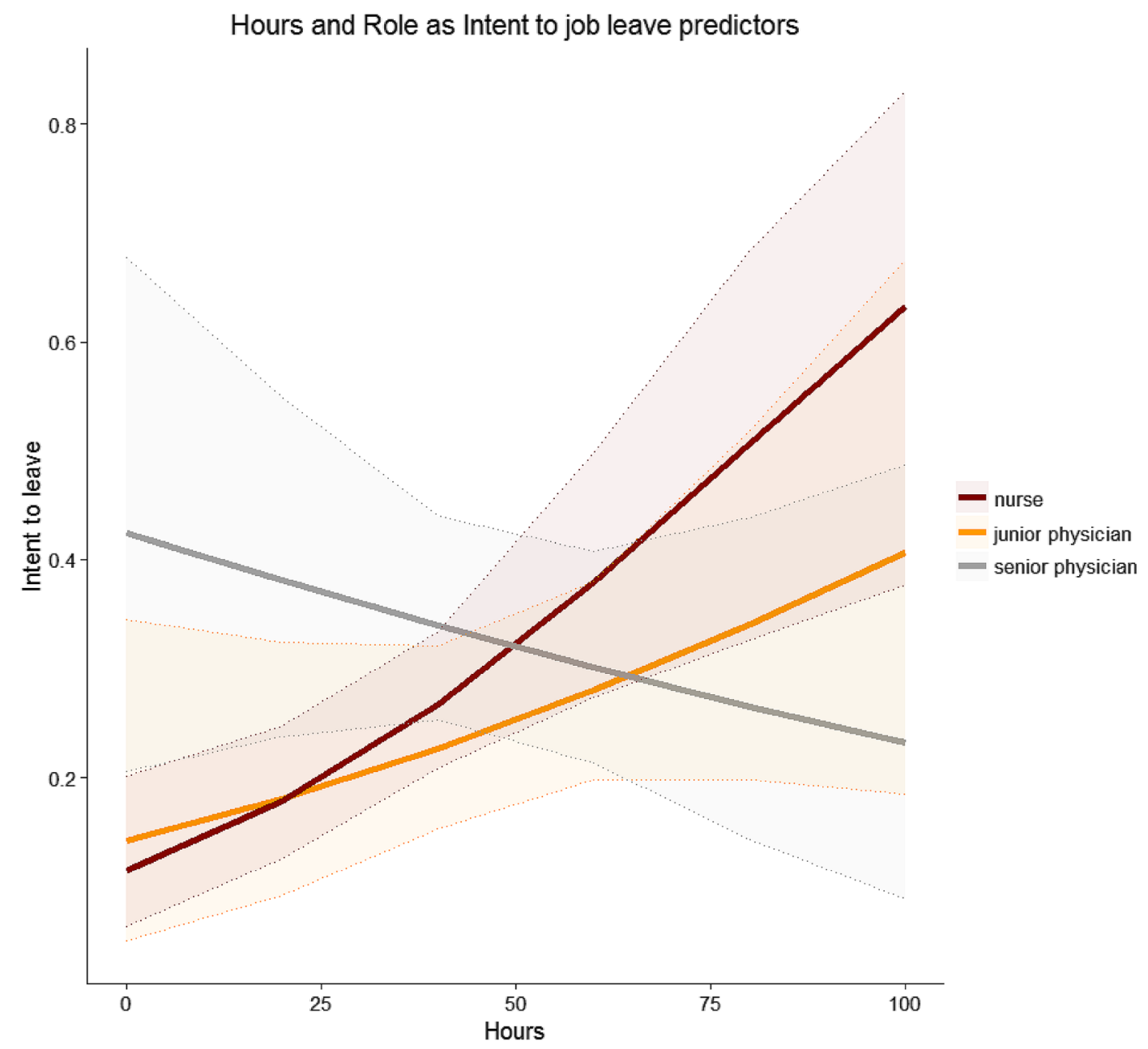

Fig. 3 Hours worked per week and professional role as intent to leave predictors. It shows how the role of the clinician interacts with the number of hours working per week. It shows predictions of the model (with interaction term) on population level (not accounting for random effect variances, i.e. a 'typical'ICU, hospital and country) of the probability for intent to job leave in function of the number of hours working per week and the role of the clinician. The intervals shown are confidence intervals for the predicted values

of EOL decisions in the ICU, were the two most important ethical climate factors associated with a lower intent to leave the job in our study. The key position of senior physicians in the EDM process $[7,8,12,14]$ and the fact that senior doctors tend to overrate their leadership- and decision-making capacities at EOL $[11,12]$ naturally points them for future interventions, especially in ICUs with a poor ethical climate [14]. Restoring meaning and a sense of wellbeing in physicians may not only improve intention to leave but might also make the ICU a highly respected and desirable place to work $[7,8,12$, $15,37]$. Every clinician needs to feel confident to promote change within the team for the benefit of the patient and their families [15, 32, 36-39]. To develop the practice of mutual respect within a team, senior physicians should act as role models [14, 20, 36-39]. This includes giving respectful feedback, empowering staff to voice perceptions and emotions, facilitating an ethical climate, where difficult decisions are not postponed but made in a timely fashion following open discussions [7, 8, 12, 14, 20, 36]. Our EDMCQ scale is a valuable addition and update to existing ethical climate scales focusing on physicians and nurses, as well as different factors within ICU units, e.g. unit physician leadership, which all have profound effects on the ethical climate $[12,14,15,20]$.

Strengths of the study include the large number and multi-national inclusion of participants, the use of a validated questionnaire to assess the ethical climate in the ICU, the high response rate of $63 \%$ and the use of logistic mixed effect models to account for correlation within ICUs and 
countries, as well as standardization to aid interpretation. Our study also has some limitations. First, the ICUs were not selected at random, which may have affected the external validity of our results. Second, all variables were measured with self-reported questions, so a common method bias may exist [40]. To increase the validity of the outcomes, assessment of actual turnover behavior ought to be included in future research. Within our cross-sectional approach, we could not enable causal interpretations [25, 27]. Future studies should longitudinally examine how ethical climate in the ICU and its outcomes develop over time, or evaluate the effect of specific interventions on the ethical climate. Finally, we did not explore meanings associated with ethical decision-making and the intent to leave, using qualitative research (e.g. focus groups). Nevertheless, the EDMCQ instrument enables ICUs to take a 'snapshot' of the EDM, as perceived by their team members. The findings of our study suggest that multidimensional interventions are necessary to address ethical climates at ICU- and individual level. Further research should focus on interview perceptions of staff members within their ICUs to create tailored and sustainable interventions to improve mutual respect, interdisciplinary reflections and active decision-making at end of life.

\section{Conclusion}

This is the first large multicenter study showing an independent association between clinicians' intention to leave their job and the quality of the ethical climate in ICU. Interventions aiming to reduce or prevent intent to leave among the ICU workforce, may be more effective when they focus on improving their ethical climate through encouraging mutual respect, open interdisciplinary reflection and active decision-making by making (senior) physicians aware of their unique position in facilitating discussions about EOL decisions.

\section{Electronic supplementary material}

The online version of this article (https://doi.org/10.1007/s00134-019-05829-1) contains supplementary material, which is available to authorized users.

\footnotetext{
Author details

1 Department of Intensive Care Medicine, Ghent University Hospital, De Pintelaan 185, Ghent, Belgium. ${ }^{2}$ King's College Hospital, London, UK. ${ }^{3}$ Department of Medical Oncology, University Medical Center Groningen, University of Groningen, Groningen, The Netherlands. ${ }^{4}$ Department of Anesthesiology and Intensive Care, First Faculty of Medicine, Charles University in Prague and General University Hospital in Prague, Prague, Czech Republic. ${ }^{5}$ Department of Intensive Care Medicine, Institute of Regional Research, Vejle Hospital, Vejle, Denmark. ${ }^{6}$ Department of Anaesthesiology and Intensive Care, Sahlgrenska University Hospital, Gothenburg, Sweden. ${ }^{7}$ University of Southern Denmark, Odense, Denmark. ${ }^{8}$ Hôpital Saint-Louis and University Paris-7, Paris, France. ${ }^{9}$ Department of Anesthesia, Critical Care, and Pain Medicine, Beth Israel Deaconess Medical Center and Harvard Medical School, Boston, MA, USA. ${ }^{10}$ Service des Medicine Interne, Soins Intensifs et Urgences Oncologiques, Institut Jules Bordet, ULB, Brussels, Belgium. ${ }^{11}$ SCDU Anestesia e Rianimazione, Azienda and Ospedaliero Universitaria, Maggiore della Carità, Novara, Italy. ${ }^{12}$ Semmelweis University Budapest, Budapest, Hungary. ${ }^{13}$ Intensive Care Department, Hospital S.António, Porto, Portugal. ${ }^{14}$ Tettnang Hospital,
}

Tettnang, Germany. ${ }^{15}$ Department of Intensive Care Medicine, Erasmus MC University Medical Center Rotterdam, Rotterdam, The Netherlands. ${ }^{16}$ Faculty of Psychology and Educational Sciences, Department of Personnel Management, Work and Organizational Psychology, Ghent University, Ghent, Belgium. ${ }^{17}$ Department of Applied Mathematics, Computer Science and Statistics, Faculty of Sciences, Ghent University, Ghent, Belgium. ${ }^{18}$ London School of Hygiene and Tropical Medicine, London, UK. ${ }^{19}$ Department of Psycho-analysis and Clinical Consulting, Faculty of Psychology and Educational Sciences, Ghent University, Ghent, Belgium. ${ }^{20}$ Department of Geriatric Medicine, Ghent University Hospital, Ghent, Belgium.

\section{Acknowledgements}

This study was supported by a European Society of Intensive Care Medicine/European Critical Care Research Network clinical research award and a Fonds voor Wetenschappelijk Onderzoek senior clinical investigators grant (1800513N) obtained in 2012 by DB. We are grateful to all the ICUs and clinicians who participated in our study and to Jolien Roels for having performed the multivariate analysis (under supervision of DB and SVS). Likewise, we would like to thank all the national coordinators (please see affiliations below).

\section{Participating centers and local investigators}

Belgium: University Hospital, Vrije Universiteit Brussel, Brussels (Herbert Spapen, Marie-Claire Van Malderen, Godelieve Opdenacker), Leuven University Hospital, Leuven (Geert Meyfroidt, Dieter Mesotten, Joost Wauters, Marie Van Laer and Alexander Wilmer, Joost Wauters, Helga Ceunen), ZNA Stuivenberg, Antwerpen (Inneke E De Laet, Anita Jans), Ghent University Hospital, Gent (Dominique Benoit, Sandra Oeyen, Ingrid Herck, Stephanie Bracke, Charlotte Clauwaert), Institut Jules Bordet, Bruxelles (Meert Anne-Pascale, Leclerca Nathalie), CHU-Brugmann, Bruxelles (Devriendt Jacques), CHU Saint Pierre, Bruxelles (Dechamps Philippe), Czech Republic: Liberec District Hospital, Liberec (Ivana Zykova), Masaryk University, Brno and University Hospital, Brno (Jan Malaska), Third Faculty of Medicine, Charles University, Prague (Matous Schmidt), Hospital and Polyclinic Havirov, Havirov (Igor Satinsky), Institute for Experimental and Clinical Medicine, Prague (Eva Kieslichova), 3rd Medical Department, First Faculty of Medicine, Charles University in Prague and General University Hospital, Prague (Jarmila Krizova), Karlovy Vary District Hospital, Karlovy Vary (Robert Janda), Pardubice District Hospital, Pardubice (Magdalena Fortova, Jiri Matyas), First Faculty of Medicine, Charles University and General University Hospital, Prague (Katerina Rusinova, Ondrej Kopecky), Denmark: Herning Hospital, Herning (Christian Alves Køhler Pedersen), Kolding Hospital, Kolding (Stine Hebsgaard), Vejle Hospital, Vejle (Rikke Frank Aagaard Johnsen), Holbæk Hospital, Holbæk (Tina Charlotte Bitsch Hansen), France: Saint-Etienne University Hospital and Jacques Lisfranc Medical School, Saint-Etienne (Michael Darmon), Saint-Louis University Hospital, APHP, Université Paris-7, Paris (Danielle Reuter, Elie Azoulay), Institut Paoli Calmette, Marseilles (Djamel Mokart), Montfermeil Hospital, Montfermeil (François Vincent), Germany: University Hospital Jena, Jena (Christiane S. Hartog), Viersen General Hospital, Viersen (Peter Gretenkort), Tettnang Hospital, Tettnang (Andrej Michalsen), Greece: Agia Olga Hospital, Athens (Aikaterini Kounougeri), Evangelismos Hospital, Athens (Serafim Nanas), Agios Pavlos Hospital, Thessaloniki (Despina Papachristou), AHEPA University Hospital, Thessaloniki, (loanna Soultati), G.Gennimatas Hospital, Thessaloniki (Dimitrios Lathyris), Hippokratio General Hospital, Thessaloniki (Marili Pasakiotou), Papageorgiou General Hospital, Thessaloniki (Marina Oikonomou), Hungary: Semmelweis University Budapest, Budapest (Gábor Élő, Orsolya Szűcs), Kaposi Mór Teaching Hospital, Kaposvár University, Kaposvár (János Fogas), St. Stephen and St. Leslie Metropolitan Hospital, Budapest (llona Bobek), Italy: Azienda Ospedaliero Universitaria, "Maggiore della Carità", Novara, and Department of Translational Medicine, Università del Piemonte Orientale, Novara (Francesco Della Corte, Carlo Olivieri, Rosanna Vaschetto, Laura Cancelliere), Ospedale Civile San Salvatore, and Department of Life, Health and Environmental Sciences (MeSVA), University of L'Aquila and Department of Emergency, San Salvatore Hospital, L'Aquila (Franco Marinangeli, Tullio Pozone, Alessandra Ciccozzi), The Netherlands: Canisius Wilhelmina Ziekenhuis, Nijmegen (A. Schouten, Monique Bruns), Medical Center Leeuwarden, Leeuwarden (RikT. Gerritsen, Matty Koopmans), Erasmus University Hospital of Rotterdam (Erwin Kompanje, Ditty van Duijn), University of Groningen and University Medical Center Groningen, Groningen (Jan G. Zijlstra, Anne KL Reyners), Wilhelmina Ziekenhuis Assen, Assen (Johan G. Lutisan), Portugal: Hospital S.António, Porto (Raquel Monte, José António Pinho, Pedro Pimenta), CHVNG, Vila Nova de Gaia (Paula Fernandes, Ana Isabel Paixão), Instituto Português de Oncologia, Porto (Filomena Faria), Sweden: 
Sahlgrenska University Hospital, Gothenburg (Johan A. Malmgren), Sahlgrenska University Hospital/Östra, Gothenburg (Bertil Andersson), Skåne University Hospital, Malmö (Eva Åkerman), Karolinska University Hospital, Karolinska (Andreas Hvarfner), The Hospital of Norrköping, Norrköping (Robert Svensson), United Kingdom: King's College Hospital, London (Victoria Metaxa), USA: Beth Israel Deaconess Medical Center and Harvard Medical School, Boston MA (Daniel Talmor, Ariel Mueller, Valerie Banner-Goodspeed), Henry Mayo Newhall Memorial Hospital, Valencia, CA (Dee Rickett), Mayo Clinic, Rochester, MN (Michael E. Wilson, Richard Hinds).

\section{Author contributions}

All authors had their substantial contributions to the conception or design of the work, or the acquisition, analysis or interpretation of data, drafting the work or revising it critically for important intellectual content and their final approval of the version published. Every author gave his/her agreement to be accountable for all aspects of the work in ensuring that questions related to the accuracy or integrity of any part of the work are appropriately investigated and resolved. Study concept and design: BB, DB, RP. Design of the questionnaire: $D B, H I J, J M, S V, E J O K, J D, B B, E A, R P$. Coordination of the translation of the questionnaire: HIJ, JM, VM, AKR, MD, KR, DT, AM, LC, LZ, PM, AM. Acquisition of

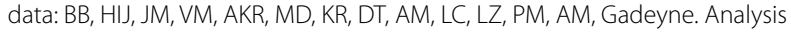
and interpretation of data: $B B, D B, S V, J R, S V$, RP. Drafting of the manuscript: $\mathrm{BB}, \mathrm{DB}, \mathrm{VM}, \mathrm{SV}, \mathrm{BB}, \mathrm{SV}, \mathrm{PV}$, RP. Critical revision of the manuscript for important intellectual content: BB, DB, HIJ, JM, VM, AKR, MD, KR, DT, AM, LC, LZ, PM, AM, SV, EJOK, JD, JR, SV, JR, EA, RP. Statistical expertise: JR, SV. Obtained funding: DB, JD. Administrative, technical, or material support: DB, JD. Steering committee: DB, SV, EJOK, JD, SV, Gadeyne, BB, EA, RP.

\section{Funding}

This study was supported by a ESCIM/ECCRN clinical research award and a FWO senior clinical investigators Grant (1800513N) obtained in 2012, and prolonged in 2017 by DDB.

\section{Compliance with ethical standards}

\section{Conflicts of interest}

The authors declare that they have no conflict of interests.

\section{Open Access}

This article is distributed under the terms of the Creative Commons Attribution-NonCommercial 4.0 International License (http://creativecommons.org/ licenses/by-nc/4.0/, which permits any noncommercial use, distribution, and reproduction in any medium, provided you give appropriate credit to the original author(s) and the source, provide a link to the Creative Commons license, and indicate if changes were made.

\section{Publisher's Note}

Springer Nature remains neutral with regard to jurisdictional claims in published maps and institutional affiliations.

\section{Received: 28 June 2019 Accepted: 10 October 2019}

Published online: 5 November 2019

\section{References}

1. Van der Heijden BIJM, Kummerling A, van Dam K, van der Schoot E, Estryn-Behar M, Hasselhorn HM (2010) The impact of social support upon intention to leave among female nurses in Europe: secondary analysis of data from the NEXT survey. Int J Nurs Stud 47(4):434-445

2. Hasselhorn HM, Tackenberg P, Muller BH (eds) (2003) Working conditions and intent to leave the profession among nursing staff in Europe. National Institute for Working Life, Stockholm

3. Coomber B, Barriball KL (2007) Impact of job satisfaction components on intent to leave and turnover for hospital-based nurses: a review of jobrelated and non-related factors. Int J Nurs Stud 44:297-314

4. Poncet MC, Toullic P, Papazian L et al (2007) Burnout syndrome in critical care nursing staff. Am J Respir Crit Care Med 175(7):698-704
5. Merlani P, Verdon M, Businger A et al (2011) Burnout in ICU caregivers: a multicenter study of factors associated to centers. Am J Respir Crit Care Med 184(10):1140-1146

6. Ackerman AD (1993) Retention of critical care staff. Crit Care Med 21(9):S394-S395

7. Piers RD, Azoulay E, Ricou B et al (2011) Perceptions of appropriateness of care among European and Israeli intensive care unit nurses and physicians. J Am Med Assoc 306(24):2694-2703

8. Piers RD, Azoulay E, Ricou B, Dekeyser GF, Max A, Michalsen A et al (2014) Inappropriate care in European ICUs: confronting views from nurses and junior and senior physicians. Chest 146(2):267-275

9. Galletta M, Portoghese I, Carta MG, D'Aloja E, Campagna M (2016) The effect of nurse-physician collaboration on job satisfaction, team commitment, and turnover intention in nurses. Res Nurs Health 39(5):375-385

10. Azoulay É, Timsit J-F, Sprung CL et al (2009) Prevalence and factors of intensive care unit conflicts: the conflicus study. Am J Respir Crit Care Med 180(9):853-860

11. Schwarzkopf D, Ruddel H, Thomas-Ruddel DO, Felfe J, Poidinger B, Matthaus-Kramer CT et al (2017) Perceived nonbeneficial treatment of patients, burnout, and intention to leave the job among ICU nurses and junior and senior physicians. Crit Care Med 45(3):e265-e273

12. Jensen HI, Hebsgaard S, Hansens TCB, et al (2019) Perceptions of ethical decision-making climate among clinicians working in European and US ICUs: differences between nurses and physicians in submission. Crit Care Med. https://doi.org/10.1097/CCM00000000000004017

13. Azoulay E, Metnitz B, Sprung CL, Timsit JF, Lemaire F, Bauer P et al (2009) End-of-life practices in 282 intensive care units: data from the SAPS 3 database. Intensive Care Med 35(4):623-630

14. Benoit DD, Jensen HI, Malmgren J, Metaxa V, Reyners AK, Darmon M et al (2018) Outcome in patients perceived as receiving excessive care across different ethical climates: a prospective study in 68 intensive care units in Europe and the USA. Intensive Care Med 44:1039-1049

15. Michalsen A et al (2019) Interprofessional shared decision-making in the ICU: a systematic review and recommendations from an expert panel. Crit Care Med 47(9):1258-1266. https://doi.org/10.1097/ CCM.0000000000003870

16. Guarino CM, Santibañez L, Daley GA (2006) Teacher recruitment and retention: a review of the recent empirical literature. Rev Educ Res 76:173-208

17. Flannery L, Ramjan LM, Peters K (2016) End-of-life decisions in the intensive care unit (ICU)-exploring the experiences of ICU nurses and doctors: a critical literature review. Aust Crit Care 29(2):97-103

18. Hämmig $O$ (2018) Explaining burnout and the intention to leave the profession among health professionals: a cross-sectional study in a hospital setting in Switzerland. BMC Health Serv Res 18(1):785

19. Austin CL, Saylor R, Finley PJ (2017) Moral distress in physicians and nurses: impact on professional quality of life and turnover. Psychol Trauma Theory Res Pract Policy 9(4):399-406

20. Van den Bulcke B, Piers R, Jensen HI, Malmgren J, Metaxa V, Reyners AK et al (2018) Ethical decision-making climate in the ICU: theoretical framework and validation of a self-assessment tool. BMJ Qual Saf 27:781-789

21. Liljegren M, Ekberg K (2009) Job mobility as predictor to health and burnout. J Occup Organ Psychol 82:317-329

22. Vyt A (2016) Interprofessional education and collaborative practice in health and social care: the need for transdisciplinary mindsets, instruments and mechanisms. In: Gibbs P (ed) Transdisciplinary professional learning and practice. Springer Publishers, Berlin, pp 69-88

23. Sexton JB, Helmreich RL, Neilands TB, Rowan K, Vella K, Boyden J et al (2006) The safety attitudes questionnaire: psychometric properties, benchmarking data, and emerging research. BMC Health Serv Res 3(6):44

24. Stogdill RM, Coons AE (1957) Leadership behavior description questionnaire (LGDQ). Oxford: Ohio State University, p 957

25. Agresti A (2013) Categorical data analysis, 3rd edn. John Wiley \& Sons, Hoboken

26. Vandenberg RJ, Nelson JB (1999) Disaggregating the motives underlying turnover intentions: when do intentions predict turnover behaviour? Hum Relat 52:1313-1336

27. Vansteelandt $\mathrm{S}$, Bekaert M, Claeskens $\mathrm{G}$ (2012) On model selection and model misspecification in causal inference. Stat Methods Med Res 21(1):7-30. https://doi.org/10.1177/0962280210387717 
28. Simon M, Muller BH, Hasselhorn HM (2010) Leaving the organization or the profession: a multilevel analysis of nurses' intentions. J Adv Nurs 66(3):616-626

29. Camerino D, Conway PM, Van der Heijden BIJM, Estryn-Behar M, Consonni D, Gould D, Hasselhorn HM (2006) Low-perceived work ability, ageing and intention to leave nursing: a comparison among 10 European countries. J Adv Nurs 56(5):542-552

30. Hamric AB, Blackhall $\amalg J$ (2007) Nurse-physician perspective on the care of dying patients in intensive care units: collaboration, moral distress, and ethical climate. Crit Care Med 35(2):422-429

31. Jensen HI, Ammentorp J, Ording H (2011) Withholding or withdrawing therapy in Danish regional ICUs: frequency, patient characteristics and decision process. Acta Anaesthesiol Scand 55(3):344-351

32. Khandelwal N, Kross EK, Engelberg RA, Coe NB, Long AC, Curtis JR (2015) Estimating the effect of palliative care interventions and advance care planning on the ICU utilization: a systematic review. Crit Care Med 43:1102-1111

33. Donovan AL, Aldrich JM, Gross AK, Barchas DM, Thornton KC, SchellChaple HM et al (2018) Interprofessional care and teamwork in the ICU. Crit Care Med 46(6):980-990

34. Mealer M (2016) Burnout syndrome in the intensive care unit future directions for research. Ann Am Thorac Soc 13:997-998
35. van Dam K, Meeuwis M, van der Heijden BI (2013) Securing intensive care: towards a better understanding of intensive care nurses' perceived work pressure and turnover intention. J Adv Nurs 69(1):31-40

36. Van den Bulcke B, Vyt A, Vanheule S, Hoste E, Decruyenaere J, Benoit $D$ (2016) The perceived quality of interprofessional teamwork in an intensive care unit: a single centre intervention study. J Interprof Care 30(3):301-308

37. Maslach C, Schaufeli WB, Leiter MP (2001) Job burnout. Annu Rev Psychol 52:397-422

38. Sokol-Hessner L, Folcarelli PH, Annas CL, Brown SM, Fernandez L, Roche SD et al (2018) A road map for advancing the practice of respect in health care: the results of an interdisciplinary modified Delphi consensus study. Jt Comm Jt Qual Patient Saf 44(8):463-476

39. Dekeyser GF, Engelberg R, Torres N, Curtis JR (2016) Development of a model of Interprofessional shared clinical decision making in the ICU: a mixed-methods study. Crit Care Med 44(4):680-689

40. Podsakoff PM, MacKenzie SB, Lee JY, Podsakoff NP (2003) Common method biases in behavioral research: a critical review of the literature and recommended remedies. J Appl Psychol 88(5):879-903 